\title{
Determinantes da Política de Remuneração do Capital Próprio: Dividendos versus Juros sobre Capital Próprio ${ }_{1}$
}

\section{Remuneration Policy' Determinants: Dividends versus Interest on Capital}

\section{Determinantes de la Política de Equidad de remuneración: Dividendos frente Intereses sobre Capital Propio}

\author{
Paulo Henrique da Cunha Pinheiro Naves Gomes \\ Bacharel em Ciências Contábeis pela Universidade Federal de Minas Gerais (UFMG) \\ Endereço: Av. Antônio Carlos, 6627, FACE/UFMG, sala 2042, Campus Universitário, Belo Horizonte, MG, Brasil,
}

CEP. 31.270-901, e-mail: paulohcpng@hotmail.com

\author{
Renata Turola Takamatsu \\ Doutora em Ciências Contábeis pela FEA-USP. Professora do Departamento de Ciências Contábeis da \\ Universidade Federal de Minas Gerais. \\ Endereço: Av. Antônio Carlos, 6627, FACE/UFMG, sala 2042, Campus Universitário, Belo Horizonte, MG, Brasil, \\ CEP. 31.270-901, e-mail: rettakamatsu@gmail.com
}

Esmael Almeida Machado

Doutor em Controladoria e Contabilidade (FEA/USP)

Professor Adjunto na Universidade Estadual de Mato Grosso do Sul (UEMS)

Vinculado ao Programa de Pós-Graduação em Desenvolvimento Regional e Sistemas Produtivos (PPGDRS) Endereço: Rua, Itiberé Vieira, S/N, Residencial Júlia de Oliveira Cardinal, Unidade Universitária da UEMS, Ponta Porã, MS, Brasil, CEP. 79907-414, e-mail: esmael@uems.br

\section{RESUMO}

Este trabalho tem o objetivo de detectar os principais fatores que levam as empresas a decidir entre distribuir seus resultados a título de dividendos ou juros sobre capital próprio das empresas listadas na BM\&FBovespa, sendo analisados, especificamente, os determinantes da distribuição de dividendos e dos juros sobre capital próprio. A política de pagamento de juros sobre capital próprio (JSCP) foi instituída pela Lei 9.249 de 1.995, e consiste na possibilidade das sociedades distribuírem aos seus investidores, juros incidentes sobre o valor do patrimônio líquido, gerando redução na carga tributária. Embora não seja obrigatório, a lei permite que o JSCP seja computado nos dividendos mínimos obrigatórios, sendo, assim, considerados uma forma de distribuição de proventos aos investidores. O presente trabalho utilizou uma técnica de regressão logística para explicar os determinantes da política de distribuição de proventos, esses determinantes foram variáveis dicotômicas assumindo resultados entre 0 (distribuir apenas dividendos) e 1 (distribuir JSCP), sobre amostra de 115 empresas brasileiras de capital aberto listadas na BM\&FBovespa. O modelo de regressão utilizado neste trabalho obteve um satisfatório nível de assertividade, o que possibilitou a análise da significância das variáveis utilizadas no modelo. Os resultados deste trabalho sugeriram que empresas do setor de construção e transporte tendem a distribuir dividendos, e, por outro

\footnotetext{
1 Artigo recebido em 29.09.2014. Revisado pelos pares em 07.03.2015 (blind review). Ajustado e Aceito para publicação em 17.07.2015. Recomendado para publicação por José Ribamar Marques de Carvalho (Editor Científico). Publicado em 05.08.2015. Organização responsável UACC/CCJS/UFCG.
} 
lado, empresas de alto valor de mercado tendem a priorizar o pagamento de JSCP. Dessa maneira, os resultados sugerem que, uma vez que o pagamento de juros sobre capital próprio é mais vantajoso do que os dividendos como forma de distribuição do excesso de caixa aos acionistas, o mercado valoriza empresas que pagam o JSCP, aumentando dessa forma o valor de mercado da empresa (Market to book).

Palavras-chave: Dividendos; juros sobre capital próprio; proventos; regressão logística.

\begin{abstract}
Our research aims to explain factors that can influence companies' remuneration policy, and specifically analyzed the determinants of dividends and interest on capital. Interest on capital established in Law No. 9,249/95, have given the possibility to societies distribute to its investors, interest on equity invested, generating a reduction in the tax payment. Although not mandatory, the law allows the interest on capital be considered as a part of the minimum mandatory dividends, and thus be considered as profit distribution form to investors. We have used a logistic regression to explain the remuneration policy, which the dependent variable were dichotomous assuming 0 (when the company only distribute dividends) and 1 (distribute interest on capital). We have analyzed a 155 Brazilian' companies traded on the BMEFBovespa. We have achieved a satisfactory level of assertiveness, allowing the significance analysis of variables used in the model. Our results suggested that companies from construction and transport sector tend to pay more dividends, and, on the other hand, high valorized market companies tend to prioritize interest on capital payment. Thus, the results suggest that, since interest on capital payment has advantages as a way to distribute cash excess to shareholders, the market values companies that pay the interest on capital, thereby increasing market values of such company.
\end{abstract}

Key-Words: Dividends; interest on capital; remuneration; logistic regression.

\title{
RESUMEN
}

Este trabajo tiene como objetivo detectar los principales factores que llevan a las empresas a decidir entre distribuyen sus resultados en forma de dividendos o intereses sobre el capital de las sociedades que cotizan en la BM E FBovespa, siendo específicamente analiza los determinantes de dividendos e intereses sobre equidad. La política de pago de intereses sobre el capital propio (JSCP) fue establecida por la Ley 9249 de 1995, y consiste en la posibilidad de las sociedades distribuyen a sus inversores, aplica sobre el valor de su capital social, generando una reducción de la presión fiscal. Aunque no es obligatorio, la ley permite que el JSCP se calcula sobre los dividendos mínimos obligatorios, y por lo tanto se considera una forma de distribución de utilidades a los inversionistas. Este estudio utilizó una regresión logística multivariante para explicar los determinantes de la política de distribución de dividendos, estos determinantes son variables dicotómicas que asumen los resultados entre 0 (sólo reparto de dividendos) y 1 (distribuir JSCP) en la muestra de 115 empresas brasileñas que cotizan que cotiza en la BM \& FBovespa. El modelo de regresión utilizado en este estudio consigue un nivel satisfactorio de asertividad, lo que permitió el análisis de la importancia de las variables utilizadas en el modelo. Estos resultados sugieren que las empresas del sector de la construcción y el transporte tienden a pagar dividendos, y, por otro lado, las empresas de mercado de alto valor tienden a priorizar el pago de intereses sobre el capital. Por lo tanto, los resultados sugieren que, puesto que el pago de intereses sobre el capital es más ventajosa que los dividendos como una forma de distribuir el excedente de efectivo a los accionistas, las empresas de valores de mercado que pagan el JSCP, lo que aumenta el valor de la empresa (mercado de reserva) del mercado.

Palabras clave: Dividendos; intereses sobre el capital; producto; regresión logística.

\section{INTRODUÇÃO}

\author{
A Política de Remuneração do Capital Próprio é um tema frequentemente \\ estudado na literatura acadêmica. Segundo Brigham et al. (2001), essa política envolve \\ a decisão de reter os lucros para expansão das empresas versus a de remunerar o capital
}

REUNIR: Revista de Administração, Contabilidade e Sustentabilidade

ISSN: 2237-3667, Vol. 5, n. 2, p.62-85, 2015 
investido pelos acionistas das empresas. Segundo os autores, a política de remuneração do capital próprio ideal busca um ponto de equilíbrio entre os lucros distribuídos e aqueles retidos com objetivos de maximizar o valor da empresa para o acionista.

Os dividendos e os juros sobre capital próprio se diferenciam por fatores, tais como a natureza jurídica, o fundamento da remuneração, sua obrigatoriedade legal e principalmente pela forma de tributação que cada um desses tipos de distribuição de resultado está sujeito. Os dividendos são distribuídos a partir do lucro líquido e não se recolhe imposto de renda sobre eles, uma vez que o lucro líquido é determinado após o recolhimento de todos os tributos que incidem sobre o resultado da empresa. É válido anotar que, no Brasil, os dividendos eram tributados até o ano de 1995. Os juros sobre capital próprio, por sua vez, são considerados dentro do grupo de despesas financeiras na demonstração de resultado do exercício da empresa, sendo, portanto, dedutíveis da base de cálculo do Imposto de Renda e da Contribuição Social sobre o Lucro Líquido, cabendo aos investidores, recolher o imposto de renda sobre esses rendimentos. Por esse motivo, os juros sobre capital próprio são vistos como uma forma de benefício fiscal para as pessoas jurídicas.

Segundo Carvalho (2003) o pagamento de juros sobre capital próprio é mais vantajoso como forma de distribuição de resultados do que os dividendos. As empresas que optam pelo pagamento de juros sobre capital próprio incorrem em um custo menor do que o que seria desembolsado na distribuição de dividendos devido à redução da carga tributária. Este quadro tende a aumentar o valor da empresa para os acionistas. Porém, observa-se que um número considerável de empresas opt am pelo pagamento de dividendos em detrimento aos juros sobre capital próprio. De acordo com informações disponibilizadas pela Secretaria da Receita Federal do Brasil em 2006, o número de empresas que decidiram pelo pagamento de juros sobre o capital próprio é, ainda, bastante reduzido, já que, no ano de 2003 , menos de $3 \%$ das companhias optantes pelo lucro real o fizeram. Contudo, nota-se que grande parte das empresas listadas na BM\&FBovespa utiliza-se dessa forma de remunerar o seu investidor.

Guerreiro e Santos (2006) verificaram em uma pesquisa realizada em 2004, que $67,2 \%$ das empresas com ações negociadas na Bovespa pagaram juros sobre o capital próprio, enquanto apenas 35,6\% das companhias listadas na Bolsa de Valores de São Paulo utilizaram esse tipo de remuneração. Esses dados foram encontrados a partir de uma amostra de 3.000 empresas que apuraram lucro no período analisado. Existem várias explicações para a existência desse comportamento, alguns autores relacionam essa situação à falta de conhecimento dos gestores em relação aos benéficos dos juros sobre capital próprio, pois, enquanto os dividendos obrigatórios foram instituídos pela Lei 6.404 de 1976, os juros sobre o capital próprio foram definidos bem mais tarde, na 
Lei 9.249 de 1995. Os dividendos já existiam no cenário brasileiro antes mesmo de 1976, porém, criou-se a necessidade da determinação dos dividendos obrigatórios para evitar que os acionistas minoritários continuassem sendo prejudicados com a retenção indiscriminada dos lucros pelas companhias. Contudo, a legislação define um limite, baseado na taxa de juros de longo prazo, para o pagamento de juros sobre capital próprio.

Segundo John e Knyazeva (2006), são vários os fatores que podem influenciar na determinação da política de remuneração de capital próprio. Para o autor, fatores como o tamanho das empresas, o nível de governança corporativa e o grau de endividamento, possuem influência direta na política de distribuição de resultados aos acionistas. Deve-se destacar que no Brasil, a tributação é um forte determinante na política de pagamento de juros sobre capital próprio e distribuição de dividendos. Nesse sentido, este estudo busca definir quais são os fatores mais impactantes para a determinação da estratégia adotada pelas empresas para distribuir seus resultados aos acionistas.

Nos últimos anos Anil e Kapoor (2008) concluíram através do seu estudo que somente a Liquidez e o Risco Sistemático (Beta) podem ser considerados como determinantes da política de dividendos. Os autores afirmam que tem havido consensos na literatura de que não há apenas uma explicação para a forma adotada para a distribuição dos lucros, mas que a política de remuneração do capital próprio continua, ainda, sendo uma questão controversa. É importante salientar, que a aplicação de conclusões de estudos internacionais podem ser, em alguns momentos, uma forma ineficaz de se analisar o mercado brasileiro, uma vez que este mercado possui peculiaridades, tais como a existência de dividendos mínimos obrigatórios ( $25 \%$ sobre o lucro líquido ajustado) e a própria existência dos juros sobre capital próprio.

Diante do exposto, o presente trabalho busca avaliar a influência de características financeiras e não financeiras sobre as decisões de como as empresas listadas na BM\&FBOVESPA distribuem seu resultado. Dessa forma, o trabalho tem o objetivo de detectar os principais fatores que levam as empresas a decidir entre distribuir seus resultados a título de dividendos ou juros sobre capital próprio.

Carvalho (2003) sugere que o pagamento de juros sobre capital próprio é mais vantajoso para as companhias, devido ao benefício fiscal da redução da base de cálculo da Contribuição Social do Lucro Líquido e do Imposto de Renda da Pessoa Jurídica que ele proporciona. Os juros sobre o capital próprio podem ser interpretados como sendo dividendos com a vantagem de serem dedutíveis da base de cálculo do imposto de renda e da contribuição social. Além deste benefício, os lucros distribuídos a título de juros sobre capital próprio poderão ser imputados no cálculo do dividendo mínimo obrigatório devido pela empresa. Segundo Nossa et al. (2007), a tributação que incide 
sobre o resultado das empresas deve ser fator de grande influência na estratégia de remuneração do capital próprio. O retorno que a ação de uma empresa gera ao seu investidor pode se dar por meio da distribuição do resultado ou do aumento no preço de sua ação, e o investidor busca encontrar a ação que lhe dê a melhor rentabilidade possível após a tributação. Portanto, a política de remuneração do capital próprio deve ser determinada com o objetivo de maximizar o retorno que as ações proporcionarão aos seus acionistas.

Em linhas gerais, a relevância deste estudo esta na sua imersão no que tange aos determinantes que levam as empresas a utilizarem os diferentes mecanismos de distribuição do resultado, juros sobre capital próprio ou dividendos, e não os determinantes que levam a empresa a distribuir ou não seus resultados. Busca-se, portanto, o delineamento das empresas mais susceptíveis a distribuir os seus resultados a partir de cada um dos métodos citados. Dessa forma, o investidor, por exemplo, poderá identificar as empresas mais sujeitas a distribuir seus resultados pelo mecanismo que mais lhe agrada.

\section{REVISÃO TEÓRICA}

As leituras utilizadas como subsidio teórico para responder a questão de pesquisa estão sumarizadas nesta seção. Para tanto, a revisão é apresentada sob três dimensões, que em seu conjunto são necessárias para o delineamento do trabalho empírico empreendido.

\subsection{A POLÍTICA DE REMUNERAÇÃO DO CAPITAL PRÓPRIO}

A remuneração do capital próprio, também chamada de distribuição dos resultados, é a forma utilizada pelas empresas para distribuir lucro aos seus investidores, remunerando, assim, o investimento feito por ele na empresa. As duas principais formas de distribuição do resultado utilizadas no Brasil são o pagamento de dividendos e dos juros sobre capital próprio, sendo esse último uma peculiaridade estabelecida pela legislação brasileira. Existem outras formas de remuneração do capital próprio previstas na legislação, como por exemplo a recompra de ações, na qual a empresa transmite parte de seus recursos financeiros através da compra de sua própria ação. Essa forma de distribuição pode ser considerada uma decisão bilateral, pois não basta a empresa decidir recomprar as ações, os investidores podem optar por mantê-las. Todavia, a recompra de ações não será analisada nesse estudo, de modo que serão consideradas apenas as duas principais formas de distribuição de resultado.

Allen e Michaely (2002) definem a política de remuneração do capital próprio como a estratégia adotada pela empresa para compensar o investidor pelo que foi 
investido por ele na empresa no momento da compra da ação. Essa estratégia deve ser formada a partir de decisões como qual a parcela do lucro que será distribuída e qual a forma de pagamento que será adotada para tal. Lintner (1956) identifica que a maior preocupação dos executivos na determinação da distribuição dos resultados está relacionada à redução dos dividendos, o que pode gerar reação negativa dos investidores e consequente perda de valor das ações da empresa.

São várias as teorias existentes que buscam explicar como as empresas definem suas políticas de remuneração de capital próprio. Gitman (1997) descreve que a política de distribuição de resultados é afetada por fatores como as reações que o mercado sofre, frente a diferentes formas de distribuição de dividendos, se dividendos fixos, contínuos ou crescentes. As empresas determinam suas políticas de forma a passar a melhor expectativa de ganhos para o investidor que eles buscam, investidores imediatistas ou investidores que buscam retornos maiores em longo prazo.

Procianoy (2003), ao tentar identificar empiricamente os fatores que afetam a política de distribuição do resultado das empresas, detectou que fatores como o crescimento e o investimento que o setor das empresas vem apresentando são determinantes da escolha da forma de distribuição do capital. $\mathrm{O}$ autor concluiu a existência de uma relação negativa com a política de dividendo, pois empresas em crescimento e que buscam novos investimentos necessitam de maiores recursos financeiros, por isso, essas empresas tendem a retê-los, causando redução na distribuição dos resultados aos acionistas. Outro fator determinante da política de remuneração do capital dos acionistas encontrado por Procianoy (2003) foi o setor de atividade da empresa. Segundo o estudo, o setor influência na política, pois setores distintos possuem diferentes necessidades de recursos e de financiamento para seus novos investimentos e capital de giro. Com isso, setores com maior necessidade de recursos, novos investimentos e ciclos de giro com sazonalidades poderão utilizar os lucros gerados para realizar o reinvestimento necessário.

Megliorini (1998), assim como Procianoy (2003), concluiu que o setor de atividade impacta na política, pois empresas que atuam em setores sazonais ou que possuem resultados com alta volatilidade possuem uma tendência de maiores retenções do lucro. Megliorini (1998) sugeriu, ainda, que o momento econômico do mercado também impacta na distribuição dos resultados, pois em épocas de expansão, as oportunidades de investimentos induzem as empresas a usar maior parte dos recursos à disposição, o que reduziria a parcela do resultado a ser distribuída para os acionistas. Por outro lado, em épocas de recessão ocorreria o contrário.

Damodaran (2002) também discorre sobre as diferentes políticas adotadas pelos setores, associando essa diferença ao risco de mercado (beta) setorial. Nesse sentido, os diferentes betas levam a diferentes retornos exigidos dos investidores, alterando, assim, a estratégia de distribuição dos resultados das empresas. Santana 
(2006) por sua vez verificou que somente a capacidade de gerar lucros estaria relacionada à distribuição dos resultados, sendo essa capacidade definida pelo ROA (Retorno sobre Ativo). Portanto, o potencial lucrativo da empresa seria, também, um fator importante para a definição da estratégia de distribuição de resultados.

Alguns outros fatores relevantes para a definição da política de remuneração do capital próprio foram indicados por Van Horne (2002), dentre eles destacam-se: as projeções de fluxo de caixa futuros, as políticas adotadas pelos concorrentes e o que os investidores esperam da empresa.

\subsection{O IMPACTO TRIBUTÁRIO SOBRE A DISTRIBUIÇÃO DOS RESULTADOS}

A tributação deve ser considerada no momento de determinar a distribuição dos dividendos, Procianoy e Verdi (2003) não conseguiram encontrar diferenças no comportamento dos investidores em relação ao dividendo não tributável e ao ganho de capital. Este estudo demonstrou um comportamento não racional do investidor brasileiro em relação à tributação sobre a forma de distribuição do resultado adotado pelas empresas.

Segundo Brito (1999), a remuneração do capital próprio através do pagamento de juros sobre capital próprio representa, em geral, uma estratégia traçada com o objetivo de diminuir a carga tributária da empresa. Porém, o autor destaca a importância de observar tal benefício bilateralmente, ou seja, essa estratégia deveria levar em consideração os benefícios aos acionistas. A possibilidade de a empresa considerar a remuneração do capital próprio como despesa financeira, significa uma alternativa para buscar a redução da carga tributária sobre a qual a entidade está submetida. Todavia, para garantir tal economia tributária, seria necessário forte planejamento tributário por parte das empresas, para garantirem a maximização do aproveitamento desse benefício e, também, para atender os requisitos previstos em lei.

Em seu trabalho, Carvalho (2003) analisa o retorno sobre o investimento dos acionistas a partir de uma comparação entre juros sobre capital próprio e dividendos. Para tal análise, foi considerado que o montante líquido recebido pelos acionistas (pessoa física) seria igual, tanto para os dividendos quanto para os juros. Os dados analisados sugeriram que a opção por remunerar próprios acionistas por meio do pagamento de juros sobre capital próprio é menos onerosa para a sociedade. $\mathrm{O}$ autor concluiu, então, que a não maximização da utilização do benefício trazido pelos juros sobre capital próprio por parte das empresas, dá-se devido ao baixo nível de conhecimento sobre ele, a desconfianças e à aversão à mudança dos seus hábitos.

\subsection{ASPECTOS LEGAIS DOS JUROS SOBRE CAPITAL}


O regulamento do imposto de Renda vigente em 1994 (Decerto 1.041/94) determinava que os pagamentos efetuados pelas companhias ao titular, sócios ou acionistas a título de juros sobre capital próprio não poderiam ser deduzidos como custo ou despesa operacional, para efeitos de determinação do lucro real. No ano de 1995, a legislação tributária concedeu às empresas tributadas pelo lucro real, através da Lei Complementar no 9.249, a opção de distribuir seus resultados por meio do pagamento de juros sobre capital próprio, oferecendo a possibilidade de dedução da base de cálculo do lucro tributável pelo imposto de renda, o montante pago a título de juros sobre capital próprio, desde que obedecidos os requisitos estabelecidos na própria Lei $\mathrm{n}^{\mathrm{o}}$ 9.249/95 e suas posteriores alterações. Apenas com o surgimento da Lei no 9.430 de 1996 o benefício da dedução dos juros sobre capital próprio foi estendido à base de cálculo da CSLL.

Segundo Fabretti (2000), a dedutibilidade dos juros sobre o capital próprio possui o objetivo de compensar a extinção e proibição, determinada pela própria Lei ${ }^{\circ}$ 9.249/95, da Correção Monetária de Balanços, que visava eliminar o efeito das perdas inflacionárias no Patrimônio Líquido e diminuir do lucro a parte referente à inflação do período. Fabretti (2000) sugere, ainda, que a criação da figura dos juros sobre capital próprio, bem como o benefício fiscal trazido por ele, seria uma forma de incentivar o investimento em atividades produtivas em detrimento das aplicações de capital em mercados meramente especulativos.

Por sua vez, Guerreiro (1996) foi preciso ao destacar que, embora tanto os dividendos quanto os juros sobre o capital próprio sejam rendimentos do capital, ambos têm tratamento fiscal diferenciado no campo interno e internacional. $\mathrm{Na}$ percepção desse autor, sua dedutibilidade para fins de apuração do imposto de renda e da contribuição social do lucro líquido é uma condição sine qua non. De maneira elegante, Guerreiro (1996) afirma que se os juros sobre o capital próprio tivessem a natureza de dividendos, a sua dedutibilidade da base de cálculo do IR seria um favor fiscal, o qual não se estenderia à apuração da CSLL, a não ser por expressa determinação legal, o que acabou por ocorrer com a Lei no 9.430/96. Ainda nesse sentido, sugeriu que os juros sobre o capital próprio deveriam ser considerados como despesa financeira para a empresa que efetuou a distribuição dos resultados por meio desse mecanismo. Isto deveria ocorrer porque, segundo Guerreiro (1996), o custo de oportunidade do capital próprio representa uma obrigação da sociedade para com o acionista, tendo, portanto, a natureza de despesa financeira.

Contudo, Torres (1997) seguiu diferente linha de raciocínio quando definiu os juros sobre capital próprio como uma espécie de dividendos, e não como despesa financeira. Essa posição assumida pelo autor é fundamentada no fato de os juros não serem fixos, dependerem da existência de lucros, poderem ser convertidos em ações, e, ainda, por serem limitados pela taxa de juros de longo prazo, que são, geralmente, 
inferiores às taxas praticadas entre pessoas não vinculadas. Soares Júnior (2001) é defensor dessa mesma opinião, baseando-se no $3^{\circ}$ do art. 192 da Constituição Federal, que descreve os juros como sendo uma remuneração da concessão de crédito, e, dessa forma, a expressão 'juros sobre o capital próprio' não é adequada ao verdadeiro significado do que ela representa, pois trata-se de uma remuneração do capital do acionista, tendo, portanto, a mesma natureza dos dividendos. Embora o autor afirme em seu trabalho que os juros sobre capital próprio tenham caráter de dividendo, ele ressalta que, a fim de evitar problemas com a fiscalização, os juros sobre capital próprio devem ser tratados como determina a lei, ou seja, como despesas financeiras.

Sob a ótica dos acionistas, essa nova alternativa de distribuição dos resultados através do pagamento de juros sore capital próprio diferencia-se dos dividendos quanto à sua tributação na fonte, pois, conforme o art. 10 da Lei 9.249/95, os dividendos não são tributados pelo Imposto de Renda na Fonte (IRRF), uma vez que tal dividendo foi tributado pelo imposto de renda da Pessoa Jurídica na apuração do lucro da sociedade, enquanto os juros sobre capital próprio seriam tributados na fonte a uma alíquota de $15 \%$, e, portanto, o montante declarado a ser recebido pelo acionista seria reduzido da parcela referente ao imposto de renda retido.

Contudo, para Neves e Viceconti (2003), o pagamento de juros sobre capital próprio traria benefícios fiscais para os dois lados da transação, tanto para o acionista, quando pessoa física, quanto para a empresa, uma vez que o acionista também seria beneficiado pela redução da carga tributária da remuneração do seu investimento, já que o ônus tributário do imposto de renda retido na fonte está sujeito à alíquota de $15 \%$, não sendo tributado pelo adicional do imposto de renda (10\%) e pela CSLL (9\%), que incidiriam sobre a apuração do lucro líquido a ser distribuído a título de dividendos.

\section{METODOLOGIA}

Nesta seção estão contemplados os elementos essenciais para operacionalização da pesquisa. Destarte, os procedimentos metodológicos são discutidos e explicados de modo a mais bem propiciar o entendimento dos resultados alcançados.

\subsection{TIPO DE PESQUISA}

O trabalho busca identificar as variáveis que explicam a determinação das empresas de suas políticas de remuneração do capital próprio, sendo estudada, especificamente, a distribuição dos lucros via juros sobre capital próprio e via pagamento de dividendos. A pesquisa é classificada como descritiva, pois busca descrever as relações existentes entre as variáveis dependentes, ou seja, aquelas que 
querem ser efetivamente estudadas, quais sejam, os dividendos e os juros sobre capital próprio, e as variáveis explicativas, que buscam explicar os impactos que elas causam nas variáveis dependentes (GIL, 1999). A abordagem adotada foi a quantitativa, diante da utilização de técnicas de regressão logística (RICHARDSON, 1999).

\subsection{AMOSTRA E FONTE DOS DADOS}

Foram inicialmente consideradas na amostra deste trabalho todas as empresas listadas na BM\&FBovespa que distribuíram algum tipo de provento aos seus acionistas no ano de 2012. Dentre as empresas que distribuíram algum tipo de proventos, foram consideradas na amostra deste trabalho apenas as empresas que distribuíram dividendos ou juros sobre capital próprio, sendo desconsideradas as empresas que não distribuíram proventos ao longo do ano 2012. Em um segundo momento, foram eliminados da amostra inicial deste trabalho os dados missing, sendo estes compostos pelas empresas em que as informações referentes à alguma das variáveis explicativas não foram encontradas no Economática. Foram eliminadas, também, as empresas consideradas como outliers, ou seja, aquelas cujo valor de alguma de suas variáveis explicativas diferenciava-se da média da amostra em mais de duas vezes o valor do desvio padrão. A amostra inicial era composta por 226 (duzentos e vinte e seis) empresas, o total de empresas eliminadas foi de 111 (cento e onze), sendo 78 (setenta e oito) desconsideradas por não terem distribuído nenhum tipo de provento no ano de 2012, 5 (cinco) foram eliminadas na exclusão de dados missing e 28 (vinte e oito) empresas retiradas pelo critério da eliminação de outliers. Dessa forma, a amostra final de dados utilizada neste trabalho foi composta por 115 (cento e quinze) empresas.

\subsection{DESCRIÇÃO DAS VARIÁVEIS}

A variável dependente utilizada foi determinada de acordo com o método de remunerar o capital próprio adotado pela empresa, em que 1 se refere à presença do atributo, no caso, a distribuição de juros sobre capital próprio (nesse contexto, consideraram-se empresas que distribuíram apenas Juros Sobre Capital Próprio - JSCP ou empresas que além dos Juros Sobre Capital Próprio - JSCP também distribuíram dividendos), e 0 a ausência desse atributo, ou seja, a empresa distribuiu apenas dividendos no período analisado. Este trabalho foi baseado em um modelo de regressão logístico capaz de exprimir o quanto índices econômico-financeiros e os setores da economia podem determinar na forma como uma sociedade listada na BM\&FBovespa distribui proventos aos seus acionistas, se sob a forma de dividendos ou de juros sobre capital próprio.

A análise logit, modelo de regressão logística utilizada neste estudo, é uma 
ferramenta comumente utilizada em trabalhos onde a variável dependente, assume um entre dois resultados possíveis ("0" ou " 1 "), sendo, portanto, uma variável binária. Segundo Fávero (2009), este modelo de regressão logística evidencia a probabilidade de determinado evento ocorrer, pois baseia-se em valores que situam-se entre 0 e 1 , onde zero é a probabilidade do evento não ocorrer e 1 a probabilidade do evento ocorrer. De acordo com a literatura sobre o tema, foram selecionados índices econômico-financeiros que poderiam explicar o fenômeno em estudo, os quais são explicitados no quadro 1.

\begin{tabular}{|c|c|c|c|}
\hline Índice & Variável & Formula & Fonte \\
\hline Rentabilidade das Vendas & rent_vendas & $\begin{array}{l}\text { Lucro Líquido/Receita } \\
\text { Líquida } \\
\end{array}$ & $\begin{array}{c}\text { Myers e Bacon } \\
(2004) \\
\end{array}$ \\
\hline Price to Earnings & $\begin{array}{c}\text { price_earning } \\
\mathrm{s}\end{array}$ & $\begin{array}{l}\text { Valor de Mercado/Lucro } \\
\text { Líquido } \\
\end{array}$ & $\begin{array}{c}\text { Myers e Bacon } \\
(2004) \\
\end{array}$ \\
\hline Market to Book & market_book & $\begin{array}{l}\text { Valor de Mercado/Patrimônio } \\
\text { Líquido } \\
\end{array}$ & $\begin{array}{l}\text { Aivazian, Booth e } \\
\text { Cleary (2003) } \\
\end{array}$ \\
\hline Liquidez Corrente & Liquidez & $\begin{array}{c}\text { Ativo Circulante/Passivo } \\
\text { Circulante }\end{array}$ & Brito (2008) \\
\hline $\begin{array}{l}\text { Número de Ações em } \\
\text { Circulação }\end{array}$ & Float & Ln (Quantidade de Ações) & $\begin{array}{c}\text { Myers e Bacon } \\
(2004) \\
\end{array}$ \\
\hline Debt to Equity & debt_equit & $\begin{array}{l}\text { Dívida Líquida/Patrimônio } \\
\text { Líquido } \\
\end{array}$ & Rozzef (1982) \\
\hline Risco Sistemático & Beta & $\begin{array}{c}\text { covar(retornos do } \\
\text { mercado;retornos do } \\
\text { ativo)/var(retornos do } \\
\text { mercado) }\end{array}$ & Rozzef (1982) \\
\hline Tamanho da Empresa & ln_at & Ln (Ativo Total) & $\begin{array}{c}\text { Damasceno et al. } \\
(2008)\end{array}$ \\
\hline $\begin{array}{l}\text { Setor de Construção e } \\
\text { Transporte }\end{array}$ & Isetor_2 & $\begin{array}{c}\text { Variável dummy } 1 \text { caso } \\
\text { pertença a esse setor e } 0 \text { caso } \\
\text { contrário }\end{array}$ & Décourt (2009) \\
\hline Setor de Consumo Cíclico & Isetor_3 & $\begin{array}{c}\text { Variável dummy } 1 \text { caso } \\
\text { pertença a esse setor e } 0 \text { caso } \\
\text { contrário }\end{array}$ & Décourt (2009) \\
\hline Setor de Consumo não Cíclico & Isetor_4 & $\begin{array}{c}\text { Variável dummy } 1 \text { caso } \\
\text { pertença a esse setor e } 0 \text { caso } \\
\text { contrário }\end{array}$ & Décourt (2009) \\
\hline Setor de Financeiro e Outros & Isetor_5 & $\begin{array}{c}\text { Variável dummy } 1 \text { caso } \\
\text { pertença a esse setor e } 0 \text { caso } \\
\text { contrário }\end{array}$ & Décourt (2009) \\
\hline Setor de Materiais Básicos & Isetor_6 & $\begin{array}{c}\text { Variável dummy } 1 \text { caso } \\
\text { pertença a esse setor e } 0 \text { caso } \\
\text { contrário }\end{array}$ & Décourt (2009) \\
\hline
\end{tabular}




\begin{tabular}{|l|c|c|c|} 
Setor de Tecnologia da & Variável dummy 1 caso \\
Informação & Isetor_7 & $\begin{array}{c}\text { pertença a esse setor e 0 caso } \\
\text { contrário }\end{array}$ & Décourt (2009) \\
\hline Setor de Telecomunicações & Isetor_8 & $\begin{array}{c}\text { Variável d } \text { ummy } 1 \text { caso } \\
\text { pertença a esse setor e 0 caso } \\
\text { contrário }\end{array}$ & Décourt (2009) \\
\hline Setor de Utilidade Pública & Isetor_9 & $\begin{array}{c}\text { Variável d } u m m y \text { caso } \\
\text { pertença a esse setor e 0 caso } \\
\text { contrário }\end{array}$ & Décourt (2009) \\
\hline
\end{tabular}

Quadro 1 - Variáveis explicativas adotadas no modelo

Fonte: Elaborado pelos autores a partir da literatura consultada.

Myers e Bacon (2004) sugeriram que companhias com maiores taxas de rentabilidade das vendas são mais propensas a remunerar o capital dos seus acionistas. Este trabalho buscou identificar se, além de influenciar na distribuição ou não de proventos, a rentabilidade das vendas de uma empresa afeta a forma como este provento é distribuído, se dividendos ou juros sobre capital próprio.

O índice Price to Earnings é utilizado para aferir o valor de mercados de uma empresa em relação ao lucro que a sociedade gera. De acordo com Myers e Bacon (2004) o incremento dos dividendos reduz o risco de futuros fluxos de caixa, o que faz aumentar o valor das ações e consequentemente o Price to Earnings. Portanto, uma vez que o índice é utilizado para determinar se uma ação está sendo super ou subvalorizada, este estudo busca verificar se esta relação é determinante para a política de remuneração do capital próprio adotada por uma empresa.

Por sua vez, o índice Market to Book mede o quanto os investidores estão dispostos a pagar por determinada ação. Em seu trabalho, Aivazian et al. (2003) utilizaram a proxy Market to Book para mensurar o valor presente das oportunidades de crescimento de uma empresa, analisando a hipótese de que grandes oportunidades de crescimento tendem a gerar uma grande retenção dos lucros por parte das empresas, causando assim baixos pagamentos proventos aos acionistas. Portanto, o presente trabalho buscou identificar se o valor pelo qual os investidores estão dispostos a pagar por uma ação no BM\&FBovespa pode influenciar na forma como uma companhia remunera o capital do seu acionista.

Conforme Silva (2010), o índice de liquidez é geralmente utilizado como uma forma de fornecer indícios da capacidade da uma companhia em honrar seus compromissos com seus credores, diante da comparação entre os direitos realizáveis e as exigibilidades. Silva (2010) explicita que a liquidez corrente indica quanto a empresa possui em dinheiro mais bens e direitos realizáveis no curto prazo, comparado com as dívidas a serem pagas no mesmo período. Este estudo buscou encontrar uma relação 
entre a necessidade de caixa para quitar as dívidas de curto prazo e a política de remuneração do capital próprio adotada por uma sociedade.

Myers e Bacon (2004) utilizam a variável Float para avaliar as ações "preferidas" dos investidores, uma vez que a maior parte dos investidores buscam ações que remunerem melhor o seu capital, e, portanto, essas seriam as ações mais negociadas na bolsa de valores. Dessa forma, este trabalhou buscou verificar se o número de ações negociadas de uma empresa pode influenciar na sua distribuição de proventos aos acionistas.

Em seu trabalho, Rozzef (1982) sugeriu que o risco associado a uma elevada alavancagem financeira poderá influenciar em uma baixa taxa de pagamento de proventos, uma vez que esta alta alavancagem gera a necessidade de retenção dos resultados da empresa para quitar suas obrigações com terceiros, deixando, dessa forma, de distribuir esse resultado aos seus acionistas. A partir da análise do debt to equity, é possível mensurar o quanto uma empresa é dependente de capital alheio. Portanto, o autor sugere uma relação inversa entre a alavancagem financeira da empresa e a remuneração do capital dos investidores, assim, este estudo buscou encontrar a relação entre a alavancagem e a forma como uma sociedade remunera o capital do acionista.

O Beta é uma ferramenta utilizada para medir o risco não-diversificável de uma ação, ou seja, fatores macroeconômicos que podem afetar todas as empresas, sendo, dessa forma, um coeficiente que indica o quanto o ativo está sujeito às variações não controláveis do mercado e do ambiente. Rozzef (1982) pressupõe que empresas com elevado Beta tendem a pagar menos proventos aos investidores, uma vez que o Beta indica encargos financeiros significativos, na medida em que Beta incorpora o risco operacional e financeiro da empresa. Assim, esperava-se aqui encontrar uma possível influência do Beta sobre a política de remuneração do capital próprio de uma companhia.

Já trabalho de Décourt (2009), esteve direcionado a identificar o quanto o setor de atuação das empresas impacta na distribuição dos resultados de uma empresa. Como resultado do seu trabalho, o autor apontou para a existência de uma tendência quanto às estratégias adotadas por empresas de um mesmo setor, pois empresas do mesmo setor apresentaram payouts semelhantes. A definição do setor de atuação das empresas foi baseada na classificação do Economática, a mesma utilizada no presente estudo como variável explicativa analisada.

\section{ANÁLISES E RESULTADOS}

Em primeira instância, o comportamento das variáveis explicativas do modelo é apresentado. É pertinente destacar que estas variáveis são formadas pelos índices 
econômico-financeiros das empresas constantes na amostra. Destarte, são analisadas a média, os desvios-padrão, os limites superiores e inferiores, bem como a matriz de correlação dessas variáveis. Insta ressaltar que das 115 empresas constantes na amostra, apenas 18 distribuíram somente JSCP no período analisado, o que significa $16 \%$ das empresas da amostra assumiram o valor "1" (distribuir apenas JSCP) referente à variável dependente do modelo ora proposto.

Tabela 1 - Análise das médias, desvios - padrão, mínimos e máximos das variáveis explicativas

\begin{tabular}{l|r|r|r|r}
\hline \multicolumn{1}{c|}{ Variáveis } & \multicolumn{1}{c}{ Desvio Padrão } & \multicolumn{1}{c}{ Média } & Limite Superior & \multicolumn{1}{c}{ Limite Inferior } \\
\hline rent_vendas & 11,26801 & 1,15181 & 23,68783 & $-21,38422$ \\
\hline price_earnings & 70,22180 & 25,10302 & 165,54662 & $-115,34058$ \\
\hline market_book & 5,78567 & 3,26605 & 14,83739 & $-8,30529$ \\
\hline Liquidez & 13,15605 & 3,11884 & 29,43093 & $-23,19325$ \\
\hline Float & 2,03529 & 12,16533 & 16,23591 & 8,09474 \\
\hline debt_equit & 102,61246 & 37,58261 & 242,80754 & $-167,64232$ \\
\hline Beta & 0,47485 & 0,77609 & 1,72579 & $-0,17361$ \\
\hline ln_at & 1,64423 & 15,19061 & 18,47907 & 11,90215 \\
\hline
\end{tabular}

Fonte: Dados da pesquisa.

A partir da análise da tabela 1, é possível verificar que algumas variáveis apresentaram grandes dispersões em relação à média, ou seja, maiores desviospadrão, destacando-se a variável de Price to Earnings (razão entre o valor de mercado e o lucro) e a variável de Debt to Equity (razão entre as dívidas e o patrimônio líquido da empresa). Quanto ao Price to Earnings, entende - se que a amostra é composta por empresas com grandes diferenças de valor de mercado e, dessa forma, com resultados igualmente diferentes, o que já era esperado, uma vez que estas diferenças são comuns entre as empresas listadas na BM\&FBovespa. Quanto ao Debt to Equity, observa-se a presença de empresas com um nível de endividamento bastante elevado, enquanto outras exibiram uma estrutura de capital mais concentrada em recursos próprios, o que mostra que a amostra é bastante diversificada, sendo composta por empresas com diferentes políticas de alavancagem de capital. O baixo desvio-padrão do In_at (tamanho das empresas) demonstrou pequeno desvio-padrão $(1,64423)$, resultado já esperado, em face das empresas de capital aberto serem, em sua maioria, de grande porte.

Tabela 2-Matriz de Correlação das variáveis explicativa

\begin{tabular}{l|c|c|c|c|c|c|c|c}
\hline \multicolumn{1}{c|}{ Variáveis } & $\begin{array}{c}\text { rent_ven } \\
\mathrm{d}\end{array}$ & $\begin{array}{c}\text { price_ear } \\
\mathrm{n}\end{array}$ & mkt_book & liquidez & float2 & debt_equit & beta & ln_at \\
\hline rent_vendas & 1 & & & & & & & \\
\hline $\begin{array}{l}\text { price_earning } \\
\mathrm{s}\end{array}$ & $-0,051$ & 1 & & & & & & \\
\hline
\end{tabular}




\begin{tabular}{l|c|c|c|c|c|c|c|c} 
market_book & 0,014 & $0.275^{* * *}$ & 1 & & & & & \\
\hline liquidez & $-0,093$ & 0,05 & $-0,116$ & 1 & & & & \\
\hline float2 & $0.013^{* * *}$ & $-0,09$ & 0,123 & $-0.202^{* *}$ & 1 & & & \\
\hline debt_equit & $-0,268$ & $-0,039$ & 0,084 & $-0.344^{* * *}$ & $0.238^{* *}$ & 1 & & \\
\hline Beta & $-0.206^{* *}$ & $-0.163^{*}$ & $-0,062$ & $0.229^{* *}$ & 0,081 & 0,103 & 1 & \\
\hline ln_at & 0,086 & $-0,092$ & $-0,096$ & $-0.308^{* * *}$ & $0.777^{* * *}$ & $0.292^{* * *}$ & $-0,014$ & 1 \\
\hline
\end{tabular}

Fonte: Dados da pesquisa.

Dentre as correlações das variáveis explicativas acima relacionadas, as variáveis que apresentaram o maior grau de correlação foram o float2 (número de ações em circulação) e o In_at (tamanho da empresa) no valor de 0,7769, fato que este que ocorre, pois, empresas maiores tendem a possuir maior número de ações em circulação na bolsa de valores. Mesmo apresentando-se em um patamar inferior a 0,8, valor que, segundo Gujarati (2006) indica um elevado nível de multicolinearidade, a inclusão conjunta dos indicadores poderia vir a influenciar na confiabilidade das análises das variáveis explicativas, o que levou a uma maior atenção durante a estimação das regressões.

Conforme Carvalho (2003), o pagamento de juros sobre capital próprio é mais vantajoso como forma de distribuição de resultados do que os dividendos. Uma vez que o JSCP é tributado à alíquota de 15\% (alíquota pessoa física) e considerado dedutível para fins de apuração do Lucro Real, desde que dentro dos limites previsto na Lei. Dessa forma, espera-se que todas as empresas realizem o pagamento de juros sobre capital próprio preferencialmente aos dividendos.

Tabela 3 - Regressão Logística para o pagamento de JSCP

\begin{tabular}{|c|c|c|c|c|c|c|}
\hline \multicolumn{4}{|c|}{ Número de Observações =111 } & \multicolumn{3}{|c|}{ LR chi2 $(15)=47,51$} \\
\hline \multicolumn{4}{|l|}{ Pseudo R2 = 0,3109 } & \multicolumn{3}{|c|}{ Prob $>$ chi $2=0,0000$} \\
\hline Distribuição de JSCP & $\begin{array}{c}\text { Coeficient } \\
\mathbf{e} \\
\end{array}$ & Erro-padrão & $\mathbf{z}$ & $P>|z|$ & $\begin{array}{r}\text { Interv } \\
\text { confian }\end{array}$ & $\begin{array}{l}\text { de } \\
5 \%)\end{array}$ \\
\hline rent_vendas & $-1,18$ & 1,138 & $-1,04$ & 0,3 & $-3,409$ & 1,05 \\
\hline price_earnings & $-0,015$ & 0,01 & $-1,45$ & 0,147 & $-0,035$ & 0,005 \\
\hline market_book & 0,687 & 0,195 & 3,53 & 0 & 0,306 & 1,068 \\
\hline Liquidez & $-0,329$ & 0,281 & $-1,17$ & 0,242 & $-0,88$ & 0,222 \\
\hline float2 & $-0,341$ & 0,323 & $-1,06$ & 0,291 & $-0,973$ & 0,291 \\
\hline debt_equit & $-0,021$ & 0,006 & $-3,48$ & 0,001 & $-0,032$ & $-0,009$ \\
\hline Beta & $-0,312$ & 0,681 & $-0,46$ & 0,647 & $-1,647$ & 1,024 \\
\hline ln_at & 0,58 & 0,326 & 1,78 & 0,075 & $-0,059$ & 1,218 \\
\hline _Isetor_2 & $-4,389$ & 1,432 & $-3,07$ & 0,002 & $-7,196$ & $-1,583$ \\
\hline
\end{tabular}




\begin{tabular}{l|r|r|r|r|r|r} 
_Isetor_3 & $-3,568$ & 1,527 & $-2,34$ & 0,019 & $-6,562$ & $-0,574$ \\
\hline _Isetor_4 & $-3,33$ & 1,482 & $-2,25$ & 0,025 & $-6,235$ & $-0,424$ \\
\hline IIsetor_5 & $-3,47$ & 1,713 & $-2,03$ & 0,043 & $-6,827$ & $-0,114$ \\
\hline _Isetor_6 & $-2,833$ & 1,452 & $-1,95$ & 0,051 & $-5,678$ & 0,013 \\
\hline IIsetor_7 & $-5,026$ & 2,942 & $-1,71$ & 0,088 & $-10,792$ & 0,739 \\
\hline _Isetor_8 & 0 & (omitido) & & & & \\
\hline _Isetor_9 & $-2,509$ & 1,517 & $-1,65$ & 0,098 & $-5,482$ & 0,464 \\
\hline _cons & $-0,52$ & 3,233 & $-0,16$ & 0,872 & $-6,856$ & 5,816 \\
\hline
\end{tabular}

Fonte: Dados da pesquisa.

Observa-se primeiramente que pela estatística que quadrado de 47,51 (Prob > chi2 $=0,0000$ ) o modelo estimado apresentou-se estatisticamente significativo. Os resultados obtidos sugerem que dentre todas as variáveis utilizadas, inicialmente, apenas as variáveis Market to book, debt to equity e Isetor_2 (Setor de construção e transporte), foram estatisticamente significativo a um nível de $5 \%$ de significância, uma vez que os seus valores-p (Z) estão abaixo de 0,05. Após a utilização do método stepwise, algoritmo estatístico que avalia a importância de cada variável independente e as inclui ou exclui do modelo segundo uma determinada regra (BRITO, 2008), obtiveram-se os resultados apresentados na Tabela 4.

Tabela 4 - Regressão logística através do método stepwise

\begin{tabular}{|c|c|c|c|c|c|c|}
\hline \multicolumn{4}{|c|}{ Número de Observações =111 } & \multicolumn{3}{|c|}{ LR chi2 $(15)=20.06$} \\
\hline \multicolumn{4}{|l|}{ Pseudo R2 = 0,131 } & \multicolumn{3}{|c|}{ Prob $>$ chi $2=0,000$} \\
\hline $\begin{array}{c}\text { Distribuição de } \\
\text { JCP } \\
\end{array}$ & $\begin{array}{c}\text { Coeficient } \\
\text { e }\end{array}$ & Erro-padrão & $\mathbf{Z}$ & $\begin{array}{c}\mathrm{P}>\mathrm{I} \mathbf{z} \\
\mathrm{I} \\
\end{array}$ & Intervalo de cc & $(95 \%)$ \\
\hline _Isetor_2 & -1.889 & 0.584 & -3.230 & 0.001 & -3.034 & -0.744 \\
\hline market_book & 0.360 & 0.130 & 2.780 & 0.005 & 0.106 & 0.614 \\
\hline _cons & -0.249 & 0.334 & -0.750 & 0.456 & -0.903 & 0.405 \\
\hline
\end{tabular}

Fonte: Dados da pesquisa.

O índice de Debt to Equity não foi incluído e analisado no modelo estimado pelo método stepwise, como no modelo completo: provavelmente porque as inter-relações entre o indicador debt-equity e as demais variáveis não significativas (agora excluídas), interferiram na análise de sua real significância. Apenas as variáveis Market to book e ser do setor de construção e transporte (Isetor_2) obtiveram coeficientes estatisticamente significativos, a um nível de $5 \%$ de significância, conforme os pvalores da estatística $Z$ (normal), os quais se situaram abaixo de 0,05. Observa-se que o índice Isetor_2 possui sinal negativo, o que indica que empresas que fazem parte do setor econômico de construção e transporte apresentam menor probabilidade de 
distribuição de Juros Sobre o Capital Próprio. Por outro lado, o índice Market to Book apresentou sinal positivo, conforme já esperado, o resultado indica que quanto maior o valor de mercado em relação ao Patrimônio Líquido de sociedade, maior serão as chances de essa empresa distribuir proventos a título de juros sobre capital próprio. Quanto aos efeitos marginais dessas variáveis dependentes, temos:

Tabela 5 - Efeitos marginais das variáveis explicativas

\begin{tabular}{l|r|r|r|r|r|r}
\hline \multicolumn{1}{c|}{ Variável } & \multicolumn{1}{c|}{$\mathbf{d y} / \mathbf{d x}$} & $\begin{array}{c}\text { Desvio- } \\
\text { Padrão }\end{array}$ & \multicolumn{1}{c|}{$\mathbf{Z}$} & \multicolumn{2}{c}{ P>|z| } & \multicolumn{2}{c}{ Intervalo de Confiança (95) } \\
\hline _Isetor_2 & $-0,431$ & 0,107 & $-4,02$ & 0 & $-0,641$ & $-0,221$ \\
\hline market_book & 0,088 & 0,038 & 2,8 & 0,005 & 0,027 & 0,151 \\
\hline
\end{tabular}

Fonte: Dados da pesquisa.

Portanto, o modelo sugere que o aumento de uma unidade em relação ao valor médio da variável Market to Book de uma empresa, a probabilidade desta pagar juros sobre capital próprio aos seus acionista aumentaria em torno de $8 \%$. Já em relação à outra variável estatisticamente significativa do modelo, sendo uma empresa do setor de construção e transporte, a probabilidade de pagar juros sobre capital próprio diminuiria em cerca de $43 \%$.

Uma classificação realizada para avaliar a qualidade do modelo proposto neste trabalho foi a capacidade explicativa do modelo, para tal classificação foram comparadas as formas de distribuição de proventos estabelecidas pelo modelo com a forma de distribuição efetivamente utilizada pelas empresas que fizeram parte da amostra.

Tabela 6 - Matriz de Classificação do Modelo Logístico

\begin{tabular}{c|c|c|c|c}
\hline \multirow{2}{*}{ Observado } & \multicolumn{2}{|c|}{ Estimado } & \multirow{2}{*}{ Total } & Classificações corretas \\
\cline { 2 - 4 } & JSCP & DIVIDENDOS & & $\mathbf{6 3 \%}$ \\
\hline Pagou JSCP & 49 & 29 & 78 & $64 \%$ \\
\hline Não pagou JSCP & 12 & 21 & 33 & $\mathbf{6 4 \%}$ \\
\hline Total & $\mathbf{6 1}$ & $\mathbf{5 0}$ & $\mathbf{1 1 1}$ & \\
\hline
\end{tabular}

Fonte: Dados da pesquisa.

Os dados acima indicam que, das 61 empresas que pagaram juros sobre capital próprio aos seus acionistas, 49 foram corretamente classificadas no modelo como de referido nível (80\% de sensitividade), enquanto 21 do total de 50 empresas que pagaram apenas dividendos aos seus acionistas foram classificadas corretamente ( $42 \%$ de especificidade). Dessa forma, nota-se a ocorrência de uma melhor sensitividade, o que significa que o modelo foi mais assertivo na predição do evento de interesse, o pagamento de juros sobre capital próprio, do que a ocorrência dos valores nulos. $\mathrm{O}$ Count $\mathrm{R}^{2}$ ( $\mathrm{n}^{\mathrm{o}}$ de previsões corretas / $\mathrm{n}^{\mathrm{o}}$ de observações) indica que o modelo previu corretamente $64 \%$ das empresas consideradas na amostra. 
Importante, ainda, realizar a análise da qualidade de discriminação do modelo, através da curva ROC (Receiver Operating Characteristic, ou seja, a curva de sensitividade e especificidade. Tal curva, segundo Hosmer e Lemeshow (2000), tem o objetivo de demonstrar a probabilidade do modelo detectar os verdadeiros sinais (sensibilidade) e os falso sinal (1-especificidade) a partir de um intervalo de possíveis pontos de corte, ou seja, a aplicação da curva ROC permite a validação do modelo medindo a assertividade do mesmo. O modelo de regressão logística apresentado que a área sob a curva ROC corresponde ao valor de 0,7318 , o que significa que o modelo possui aceitável poder discriminante, conforme proposto por Hosmer e Lemeshow (2000).

Os resultados obtidos através do modelo de regressão proposto neste trabalho foram, de uma forma geral, os resultados inicialmente esperados. Uma vez que a variável explicativa market to book foi considerada como significativa como determinante na política de remuneração do capital próprio de uma empresa que negocia ações na BM\&FBovespa. O benefício fiscal da dedutibilidade dos juros sobre capital próprio pago aos acionistas de uma sociedade na apuração do seu imposto de renda da pessoa jurídica e sua contribuição social sobre o lucro líquido, por si só, já é um motivo suficientemente forte para que as empresas deem preferência ao pagamento do JSCP em detrimento a distribuição de dividendos. O resultado, portanto, vai ao encontro com o trabalho de Carvalho (2003), que sugere que o pagamento de juros sobre capital próprio é mais vantajoso do que os dividendos como forma de distribuição do excesso de caixa aos acionistas, o que explica a boa forma como o mercado vê as empresas que pagam o JSCP, aumentando dessa forma o valor de mercado da empresa (Market to book).

Contudo, esperava-se que a variável Debt to Equity apresentasse um resultado estatisticamente significativo e sinal negativo em relação ao pagamento de JSCP, pois, conforme Modigliani e Miller (1963) a vantagem fiscal da dedutibilidade das despesas financeiras das divididas com terceiros poderiam ser, até certo ponto, trocadas pela alavancagem de capital por meio do capital próprio, e o pagamento dos juros sobre capital próprio. Essa estrutura de capital tenderia a diminuir a participação do capital de terceiros nas empresas que pagam o JSCP, pois este eliminaria a vantagem fiscal da dívida. Porém, o resultado da regressão deste trabalho sugere que a variável não é significativa a um nível de confiança de $95 \%$.

O trabalho de Santana (2006) indicou que o setor econômico de uma empresa possui influência sobre o seu índice de payout (taxa de pagamento de proventos), dessa forma, esperava-se que o setor da economia pudesse, também, influenciar na forma como o provento é distribuído. Tal influencia foi verificada no modelo utilizado neste trabalho no setor econômico-financeiro de construção e transporte. Importante ressaltar, porém, ser este setor apenas um dos 9 (nove) setores analisados no modelo, 
o que sugere que a embora exista a influência, o setor econômico pode ser uma forma fraca de explicar a política de remuneração do capital próprio de uma empresa.

O resultado obtido a partir do modelo proposto neste estudo foi limitado a apenas 2 (duas) variáveis explicativas estatisticamente significativas, o índice markt to book e o fato de ser do setor de construção e transporte, portanto, apenas 2 das 16 variáveis explicativas utilizadas no modelo, o que representa aproximadamente $13 \%$ das variáveis explicativas. Ressalta-se que o número pouco expressivo de empresas consideradas na amostra incluída no modelo, 115 empresas no total, uma vez que, adveio do fato de grande parte da amostra inicial foi desconsiderada por não preencher os requisitos necessários para fazer parte da amostra, ou seja, empresas listadas na BM\&FBovespa que não distribuíram nenhum tipo de proventos.

Outra limitação do presente trabalho consiste na possibilidade de que existam empresas que, embora deem prioridade ao pagamento dos juros sobre capital próprio aos seus acionistas, distribuam dividendos aos seus acionistas, pois, uma vez que tenham atingido o limite do benefício da dedutibilidade do JSCP previsto na legislação, a empresa poderia optar por distribuir dividendos, pois não haveria mais que se falar em dar prioridade a pagar o JSCP, pois seu benefício fiscal já teria sido totalmente utilizado. Tal situação gerada pela legislação fiscal brasileira levaria a empresa a ser desconsiderada na amostra utilizada no modelo deste trabalho, ainda que essa empresa possa ser enquadrada como pagadora de JSCP.

\section{CONSIDERAÇÕES FINAIS}

O principal objetivo deste trabalho consistiu em detectar os principais fatores que levam as empresas a decidir entre distribuir seus resultados a título de dividendos ou juros sobre capital próprio das empresas listadas na BM\&FBovespa, uma vez que a legislação brasileira prevê a existência de duas principais formas de pagamento de proventos aos investidores, quais sejam a distribuição de dividendos e o pagamento de juros sobre capital próprio, sendo esta última uma peculiaridade da legislação brasileira. Diante do benefício fiscal da dedutibilidade do JSCP na apuração do Imposto de Renda a pagar e da Contribuição Social Sobre o Lucro Líquido de uma sociedade, esperava-se que todas as empresas usufruíssem deste benefício, e apenas após atingir o limite desta dedutibilidade fossem distribuídos os dividendos.

Uma explicação plausível para este comportamento seria de que os investidores seriam avessos ao JSCP, pois parte do seu provento é retido na fonte a título de Imposto de Renda e tal retenção é destacada no informe de rendimento do investidor. Por outro lado, o investidor que recebe dividendos não tributa essa remuneração, uma vez que este foi tributado na apuração do Lucro Real da sociedade. Contudo, tal comportamento seria equivocado, e, portanto, apenas investidores desinformados 
prefeririam os dividendos aos juros sobre capital próprio, pois, em uma análise da carga tributária, sabe-se que á alíquota do imposto de renda retido na fonte (15\%), é inferior à alíquota da pessoa jurídica, que somada à alíquota da Contribuição Social, é, geralmente, de $34 \%$ (trinta e quatro por cento).

$\mathrm{O}$ modelo proposto neste trabalho identificou que o mercado reage bem ao pagamento de juros sobre capital próprio por parte das empresas listadas na bolsa, uma vez que foi verificado no comportamento da a variável explicativa Market to Book que esta tende a apresentar um patamar mais elevado quando uma empresa é pagadora de JSCP. O que significa que o mercado avalia essas empresas de forma positiva, tendo então seu valor de mercado maior do que seu valor de Patrimônio Líquido, tal comportamento pode ser interpretado, ainda, como um indício que os investidores são bem informados quanto à carga tributária dos seus investimentos.

A segunda variável estatisticamente significativa do modelo proposto foi a "ISetor_2", formada pelas empresas do setor econômico de construção e transporte listadas na BM\&FBovespa que distribuíram apenas um tipo de provento aos seus acionistas em 2012, sendo estes os dividendos ou o JSCP. O resultado obtido sugere que estas empresas são preponderantemente distribuidoras de dividendos. Uma possível explicação para este fato está na alta margem de lucro e nos costumes da empresa, pois tais empresas são geralmente bastante antigas e o JSCP é relativamente novo, sendo criado em 1995 quando foi estabelecido na Lei Complementar 9.249, e dessa forma, as empresas podem sofrer algum tipo de resistência a mudanças. Pelo fato de possuírem alta margem de lucro, essas empresas são grandes distribuidoras de proventos. Logo, seu limite de dedutibilidade do JSCP é costumeiramente esgotado, o que pode, também, torná-lo não tão atrativo assim, o que explicaria a preferência pelos dividendos.

Observa-se dessa maneira, que apesar de o trabalho explicitar que apenas a variável market-to-book foi detectada como uma variável estatisticamente significativa para explicar a escolha de remuneração dos acionistas, o trabalho explicita uma área frutífera de pesquisa. Assim, mostra-se relevante a realização de pesquisas que ampliem a amostra, considerando a evolução temporal da distribuição do Juros Sobre Capital, dado a compreensão crescente dos gestores/investidores sobe essa forma de remuneração. Em adição variáveis adicionais financeiras e não financeiras podem ser incluídas no modelo, levando-se em consideração aspectos tributários bem como do nível de comprometimento das instituições, tais como o nível de governança corporativa.

\section{REFERÊNCIAS}


AIVAZIAN, V. et al. Do Emerging Market Firms Follow Different Dividend Policies from U.S. Firms?. The Journal of Financial Research, vol. 26, n. 3, p. 371-387, 2003.

ALLEN, F.; MICHAELY, R. Payout Policy. Social Science Research Network Eletronic Library, Working Paper, abr. 2002.

ANIL, K.; KAPOOR, S. Determinants of Dividend Payout Ratios-A Study of Indian Information Tecnology Sector. In International Research Journal of Finance and Economics, Vol. 15, p. 63-71, 2008.

BRASIL. Lei $n^{\circ}$ 6.404, de 15 de dezembro de 1976. Dispõe sobre as Sociedades por Ações. Diário Oficial da União. Brasília, 17 de dezembro, p1 (suplemento), 1976.

BRASIL. Lei nº 9.249 de 26 de dezembro de 1995. Altera a legislação do imposto de renda das pessoas jurídicas, bem como da contribuição social sobre o lucro líquido, e dá outras providências. Diário Oficial da União, Seção 1, p 22301, Brasília, 37 de dezembro, 1995.

BRASIL. Lei nº 9.430 de 27 de dezembro de 1996. Dispõe sobre a legislação tributária federal, as contribuições para a seguridade social, o processo administrativo de consulta e dá outras providências. Diário Oficial da União, Seção 1, p 28805, Brasília, 30 de dezembro, 1996.

BRIGHAM, E. F., et al.. Administração financeira: teoria e prática. Tradução Alexandre Loureiro Guimarães Alcântara e José Nicolas Albuja Salazar. São Paulo: Atlas, 2001.

BRITO, G. A. S.; NETO, A. A. Modelo de Classificação de Risco de Crédito de Empresas. Revista Contabilidade \& Finanças [online].São Paulo, vol.19.n.46.p.1829.2008.

BRITO, M. Planejamento tributário: imposto de renda. Vila Velha: SEDES/UVV, 1999.

CARVALHO, E. R. A. Política de dividendos e juros sobre capital próprio: um modelo com informações assimétricas. Dissertação (Mestrado, Administração de Empresas) FGV/ Escola de Administração de Empresas de São Paulo, São Paulo, 2003. 
DAMASCENO, D. L. et al.. Determinação de rating de crédito de empresas brasileiras com a utilização de índices contábeis. RAUSP [online]. São Paulo, vol. 43.n.4.2008.

DAMODARAN, A. A Face Oculta da Avaliação: Avaliação de Empresas da Velha Tecnologia, da Nova Tecnologia e da Nova Economia. São Paulo: Makron Books, 2002.

DÉCOURT, R. F. O Processo Decisório da Distribuição de Lucros das Empresas Listadas na Bovespa. Tese de Doutorado (Administração) - Universidade Federal do Rio Grande do Sul, Porto Alegre, 2009.

FABRETTI, L. C. Contabilidade Tributária. 6. ed. São Paulo: Atlas, 2000.

GIL, A. C. Métodos e técnicas de pesquisa social. São Paulo: Atlas, 1999.

GITMAN, L. J. Princípios de administração financeira. 7 ạ ed. São Paulo: Harbra, 1997.

GUERREIRO, R.N. Juros sobre o capital. In: ROCHA, Valdir de Oliveira (coord.). Imposto

de renda: alterações fundamentais. São Paulo: Dialética, p.201-13. 1996.

GUERREIRO, R.; SANTOS, A. As empresas que operam no Brasil estão pagando juros sobre o capital próprio? Congresso USP Controladoria e Contabilidade, 6, 2006, São Paulo. Anais. Disponível em <www.Congressoeac.locaweb. com.br/artigos 62006>. Acesso em: 10/10/2007.

HOSMER, D.; LEMESHOW, S. Applied logistic regression. 2. ed. New York: John Wiley \& Sons. p. 260-280, 2000.

JOHN, K.; KNYAZEVA, A. Payout policy, agency conflicts, and corporate governance. Working paper, New York University, 2006.

LINTNER, J. Distribution of incomes of corporations among dividends, retained earnings, and taxes. American Economic Review, v. 46, p.97-113, 1956.

MEGLIORINI, E. Lucros Distribuídos - Fator de Atratividade para Investimentos em Ações. Editora Faculdade de Ciências Econômicas e Administrativas de Osasco 1998. 
MYERS, M.; BACON, F. The determinants of corporate dividend policy, Academy of Accounting and Financial Studies Journal, Vol. 8, N. 3, p. 17-28, 2004.

NEVES, S.; VICECONTI, P. E. V. Curso Prático de Imposto de Renda Pessoa Jurídica e tributos conexos: (CSLL, PIS e COFINS). 10. ed. São Paulo: Frase Editora, 2003

NOSSA, S. N. et al.. As empresas que distribuem dividendos são mais eficientes? In: Congresso USP de Controladoria e Contabilidade,7, (Faculdade de Economia, Administração e Contabilidade da Universidade de São Paulo), 2007, São Paulo. Anais... São Paulo: USP, CD-ROM. 2007.

PROCIANOY, J. L; HEINEBERG, R., Aspectos Determinantes do Pagamento de Proventos em Dinheiro das Empresas com Ações Negociadas na Bovespa. XXVII ENANPAD; 2003.

PROCIANOY, J. L.; VERDI, R. O efeito Clientela no Mercado Brasileiro: Será que os investidores são irracionais? Revista Brasileira de Finanças, vol. 1, n.2, 2003.

RICHARDSON, R. J. Pesquisa Social: Métodos e Técnicas. São Paulo: Atlas, 1999.

ROZEFF, M. S. Growth, Beta and Agency Costs as Determinants of Dividend Payout Ratios, The Journal of Financial Research, Vol. V, N. 3, p. 249-259, 1982.

SANTANA, L. Relação entre dividend yield e retorno das ações abordando aspectos determinantes da política de dividendos: um estudo empírico em empresas com ações negociadas na BOVESPA. 2006. 82 f. Dissertação (Mestrado em Ciências Contábeis) Fundação Instituto Capixaba de Pesquisas em Contabilidade, Economia e Finanças, Vitória, 2006.

SILVA, J. P. Análise Financeira das Empresas. 10.ed.São Paulo: Atlas, 2010.

SOARES JÚNIOR, L. Modelo para avaliação do impacto dos juros sobre o capital próprio na estrutura de capital e no fluxo de caixa das empresas. Dissertação (Mestrado em Engenharia de Produção) Universidade Federal de Santa Catarina. 2001.

VAN HORNE, L.C. Financial Management and Policy, 10 ed. New Jersey: Prentice Hall; 2002. 